\title{
Surgical considerations about shaver adenoidectomy: our experience
}

\author{
D.C. GHEORGHE ${ }^{1}$, A. ZAMFIR-CHIRU-ANTON² \\ ${ }^{1}$ „M.S. Curie“ Clinical Hospital for Children, „Carol Davila“ University of Medicine and Pharmacy, \\ Bucharest \\ 2"Grigore Alexandrescu" Emergency Clinical Hospital for Children, Bucharest
}

\begin{abstract}
Adenoidectomy is a very common surgical procedure in pediatric otolaryngology.

Aim. To investigate two major operative techniques used for pediatric adenoidectomy (classic and using microdebrider), from a surgical point of view. Ease of use, comfort of the surgeon and possible intraoperative difficulties were studied and reported here.

Material and method. A series of 93 patients were randomly assigned to two kind of surgery. Parameters like introperative blood loss, duration of the surgery and accuracy of the technique were assesed.

Conclusions. Both techniques can consume similar amount of time. Blood loss is significantly higher with microdebrider but better surgical accuracy is obtained through powered instrumentation.
\end{abstract}

Keywords: adenoidectomy, microdebrider

Adenoidectomy is one of the most common surgeries performed in pediatric otolaryngology (1). The relative ease of the procedure, short time of admission and usually fast recovery have maintained this operation on top of pediatric ENT manoeuvers. The indications for adenoidectomy have always been a subject of debate but otitis media, obstructive sleep apnea and chronic nasal obstruction have always dominated the preferences of surgeons and pediatricians as well. (2)

More technical surgical procedures were developed over time. Along with the classical curette technique, coblation (3), diathermy-aspiration (4) and microdebrider (shaver)(5) have all been used to obtain good nasal patency and respiratory disease-free patients.

Most of the published studies concentrated on patient advantages as to which surgical technique should be employed from the patient's point of view (e.g. lack of complications, minimal morbidity). Our study is meant to discuss only the surgical aspect of shaver adenoidectomy versus classical curette method.

\section{MATERIAL AND METHOD}

The usual surgical technique used in our department is classical Beckmann adenotome. Recently, microdebrider became available to our surgeons. 
From the patients admitted to the otolaryngology department of MS Curie Hospital, 93 have been enrolled in the study. 50 were operated using Beckmann adenotome and 43 by shaver method. Ethical approval was obtained from the hospital and informed consent from every parent of the patients involved.

There were no demographic criteria for enrollment of a patient into a group or the opposite. No clinical differencies were taken into consideration when deciding the use of coblation or classic technique. There were 40 girls and 53 boys in the study, aged 2.5 to 6 years old.

The adenoidectomy has been performed by only one surgeon in all cases. Parameters involved for study were:

- duration of the procedure;

- number of gauze used for each patient;

- time required to obtained full hemostasis (no visible blood flowing/woozing from the operative bed)

- operative wound appearance (from the surgeon's point of view).

To better appreciate the mentioned criteria, the surgeries were performed in the same operating theatre, with the same medical staff. The time necessary to operate was calculated from the first surgical maneuver to the beginning of hemostasis. Hemostasis included the time required for the surgeon to stop any visible bleeding from the operative wound, when any cutting intervention was finished. The gauze needed for haemostasis comes roughly in the same size/ shape and has been used as long as at least $80 \%$ of visible tissue was covered/ impregnated with blood. Operative wound was examined by inspection (eye view after velar retraction) and also by palpation. A score from 1 to 10 has been attributed to express the smoothness of the posterior wall of the rhinopharynx, the lack of "bumps" and possible lymphoid remnants around the Eustachian tubal openings. A final transnasal endoscopic exam, with a straight Hopkins rod was undertaken to appreciate for lymphoid remnants.

\section{RESULTS}

The demographic data of the patients enrolled into our study is summarised in Table 1. There was no statistical difference between age of the two group of surgery $(P=0.44$, two-sample $t$-test). The mean age at surgery was 4.3-4.6 years, with range from 2 to 12 years old.
TABLE 1. Demographic data of the patients

\begin{tabular}{|l|c|c|c|}
\hline Surgical technique & Mean age & S.D. & Range \\
\hline Curette & $4.66 \mathrm{y}$ & 2.26 & $2-12 \mathrm{y}$ \\
\hline Shaver & $4.34 \mathrm{y}$ & 1.56 & $2-8 \mathrm{y}$ \\
\hline Total & $4.51 \mathrm{y}$ & 1.96 & $2-12 \mathrm{y}$ \\
\hline
\end{tabular}

Time needed for surgery showed a mean value of $4.79 \mathrm{~min}$ for curette (range from 2 to $9 \mathrm{~min}$ ) technique and $5.58 \mathrm{~min}$ (range from 4 to $9 \mathrm{~min}$ ) for microdebrider adenoidectomy. Although the difference is statistically significant $(P=0.013$, two-sample $t$-test) the absolute amount of time for performing the surgery seems similar. The measurements we obtained have been summarized in Table 2 .

TABLE 2. Obtained measurements

\begin{tabular}{|l|c|c|c|}
\hline & $\begin{array}{c}\text { Duration of } \\
\text { surgery }\end{array}$ & S.D. & Range \\
\hline Beckman curette (50) & $4.79 \mathrm{~min}$ & 1.523 & $2-9 \mathrm{~min}$ \\
\hline Shaver (43) & $5.58 \mathrm{~min}$ & 1.346 & $4-9 \mathrm{~min}$ \\
\hline
\end{tabular}

As we could notice in the OR, there has been a steep learning curve when shaver surgery was firstly performed in our department. Hence, the first operated cases were not included in this study. After proper training, the duration of powered adenoidectomy proved to be competitive with the classic method. Still, one may argue that a larger amount of time is necessary to prepare the instruments needed for adenoidectomy in case of powered surgery. We did not take that issue into account, considering the fenomenon of no surgical/ clinical significance.

The hemostasis instead proved more difficult after shaver adenoidectomy than after Beckmann technique. The time necessary to obtain full resolution of bleeding locally, was 12,5 min (range 8-17 min) for classic surgery and 17.44 min (range 14-23 min) for microdebrider. The difference is statistically significant ( $P=0.001$, two-sample t-test). That fenomenon had a clear proof considering the number of gauze used each surgery. Data is shown in Table 3.

\section{TABLE 3}

\begin{tabular}{|l|c|c|c|}
\hline & $\begin{array}{c}\text { Hemostasis } \\
\text { time }\end{array}$ & S.D. & $\begin{array}{c}\text { No of gauze } \\
\text { (pieces) }\end{array}$ \\
\hline Beckmann curette & $12.52 \mathrm{~min}$ & 2.12 & 2,96 \\
\hline Shaver & $17.44 \mathrm{~min}$ & 2.17 & 8,5 \\
\hline
\end{tabular}

The wound, examined intraoperatively, at the end of surgery, showed a better, smoother palpable posterior wall of the rhinopharynx when microdebrider was used. No lymphoid remnants were detected both by palpation and 
by transnasal endoscopic examination, on both surgical techniques.

TABLE 4

\begin{tabular}{|l|c|}
\hline & $\begin{array}{c}\text { Local rhinopharyngeal } \\
\text { evaluation (VAS) }\end{array}$ \\
\hline Beckmann curette & 9 \\
\hline Shaver & 10 \\
\hline
\end{tabular}

\section{DISCUSSION}

A lot of debate took place along the years about the best surgical approach for adenoidectomy $(3,6)$. Most of the disscussion has focused on the postoperative morbidity, mainly because we are addressing small children and because the percentage of postoperative complications remained unchanged in spite of medical advances throughout the history of our specialty. (7)

Early hemorrhage and velopharyngeal insufficiency account for most of this adenoidectomy-associated morbidity. That led to imagining surgical methods to counteract bleeding and minimise pain in operated patients. $(8,9)$ Coblation and diathermy-aspiration try achieving these goals.

Shaver, on the other hand, has long been used as a more convenient way of removing tissues from nasal cavity, with minimal bleeding and minimal traumatic supplementary lesions. (10) As we demonstratein our series of patients, the bleeding after powered adenoidectomy is higher and more difficult to control than after Beckman curette surgery. Hence, use of short term general anesthesia (GA) (e.g. without tracheal intubation) is not recomandable if we decide to go this method. The best advantage of microdebrider is that it allows a precise ablation of the lymphoid tissue, even if partially removing the adenoids. That would favor its use in cases where a short palate and uvula are obvious or already presumed (velopharyngeal insufficiency, cleft palate). Some difficult cases with small rinopharynx and small mouth opening during GA can also benefit from shaver adenoidectomy, for minimising trauma to the lateral walls of the pharynx.

Duration of the procedure is not different from the classic Beckmann adenoidectomy. Still, the cost of the procedure sometimes can make it prone to difficulty in medical systems that are financially restrictive.

Some objections to our study model can be made. One is the decision to perform shaver or classic adenoidectomy, since some of the patients operated in our department refused to enroll the study. The other refers to the limited number of cases compared.

\section{CONCLUSIONS}

Classic adenoidectomy is better in terms of quick hemostasis and low financial burden. It does not allow a precise, pinpoint excision of the lymphoid tissues, although it does not leave identifiable, obstructive remnants, from our experience.

Powered (shaver) adenoidectomy is a new technique that can be easily mastered and allows partial excision of the adenoids in special cases. It is less traumatic and very precise to the pharyngeal walls as well. It is a fast procedure but prone to hemostasis difficulties, intraoperatively. Its high instrumentation costs restrict its use to well developed and financially unrestrictive medical systems.

\section{REFERENCES}

1. Cho J.H., et al. Size assessment of adenoid and nasopharyngeal airway by acoustic rhinometry in children. $J$ Laryngol Otol, 1999. 113(10): p. 899-905.

2. Hibbert $\mathrm{J}$. The occurrence of adenoidal signs and symptoms in normal children. Clin Otolaryngol Allied Sci, 1981. 6(2): p. 97-100.

3. Timms M.S., Ghosh S., Roper A. Adenoidectomy with the coblator: a logical extension of radiofrequency tonsillectomy. $J$ Laryngol Otol, 2005. 119(5): p. 398-9.

4. Owens D., Jaramillo M., Saunders M. Suction diathermy adenoid ablation. $J$ Laryngol Otol, 2005. 119(1): p. 34-5.
5. Somani S.S., Naik C.S., Bangad S.V. Endoscopic adenoidectomy with microdebrider. Indian J Otolaryngol Head Neck Surg, 2010. 62(4): p. 427-31.

6. Cannon C.R., Replogle W.H., Schenk M.P. Endoscopic-assisted adenoidectomy. Otolaryngol Head Neck Surg, 1999. 121(6): p. 740-4.

7. Henry L.R., Gal T.J., Mair E.A. Does increased electrocautery during adenoidectomy lead to neck pain? Otolaryngol Head Neck Surg, 2005. 133(4): p. $556-61$.
8. Wynn R., Rosenfeld R.M. Outcomes in suction coagulator adenoidectomy. Arch Otolaryngol Head Neck Surg, 2003. 129(2): p. 182-5.

9. Walker P. Pediatric adenoidectomy under vision using suction-diathermy ablation. Laryngoscope, 2001. 111(12): p. 2173-7.

10. Parsons D.S. Rhinologic uses of powered instrumentation in children beyond sinus surgery. Otolaryngol Clin North Am, 1996. 29(1): p. 105-14. 